\title{
Cardiac involvement in Anderson-Fabry disease
}

\author{
Filippo Maria Cauti, ${ }^{1}$ Constantinos 0'Mahony, ${ }^{2}$ Antonis Pantazis ${ }^{2}$
}

${ }^{1}$ Cardiology Department, University of Rome 'Sapienza', Via di Grottarossa, Rome, Italy
${ }^{2}$ Inherited Cardiac Diseases Unit, The Heart Hospital, London, UK

Correspondence to Filippo Maria Cauti, filippocauti@hotmail.it

\section{Summary}

A normotensive 50-year-old man was evaluated for cardiac symptoms associated with left ventricular hypertrophy (LFH). His symptoms were caused by cardiac involvement from Anderson-Fabry disease (AFD), an X linked lysosomal storage disease caused by mutations in the GLA gene which encodes for the lysosomal enzyme -galactosidase A. He was treated with recombinant enzyme but the clinical course was complicated by arrhythmias and the patient required an internal cardioverter defibrillator.

Even though AFD is rare, this case illustrates the importance of considering the diagnosis in selected patients as effective treatment has recently become available. Recognition of AFD also allows for screening of asymptomatic relatives who may benefit from treatment before irreversible life-threatening complications develop.

\section{BACKGROUND}

Left ventricular hypertrophy (LVH) is a common clinical finding and often attributed to hypertension or hypertrophic cardiomyopathy. This case highlights rare but treatable causes of LFH that should be considered when managing such patients.

\section{CASE PRESENTATION}

A 50-year-old man presented to his local cardiology service with chest pain. He was normotensive, with a history of dyslipidaemia but not other risk factors for coronary artery disease.

His ECG had LVH by voltage criteria and repolarisation abnormalities (figure 1A). Echocardiography confirmed the presence of concentric LVH (figure 1B) which was associated with diastolic dysfunction. Coronary angiography revealed unobstructed coronary arteries and Holter monitoring non-sustained ventricular tachycardia (VT). He had proteinuria with normal creatinine clearance.

He was referred to our cardiomyopathy clinic where he was investigated for the underlying cause of LVH (see Differential Diagnosis). He was screened for AndersonFabry disease (AFD) according to our local protocol and found to have reduced plasma -galactosidase A activity (0.6 $\mathrm{nmol} / \mathrm{h} / \mathrm{ml}$, normal:4-21.9 $\mathrm{nmol} / \mathrm{h} / \mathrm{ml}$ ). Gene sequencing detected a pathogenic mutation (N215S) in the GLA gene.

\section{DIFFERENTIAL DIAGNOSIS}

The differential diagnosis of LVH in normotensive patients: ${ }^{1}$

1. hypertrophic cardiomyopathy secondary to sarcomeric gene mutations

2. AFD

3. glycogen storage disease (eg, Danon disease)

4. mitochondrial cytopathies

5. Freidreich's ataxia

6. syndromic 'HCM' (eg, Noonan's syndrome)

7. amyloid

8. athletic training.

\section{TREATMENT}

Once the diagnosis of AFD was reached, the patient was started on enzyme replacement therapy which consisted of biweekly intravenous infusions of recombinant-galactosidase A. The treatment was tolerated well.

\section{OUTCOME AND FOLLOW-UP}

Three years after diagnosis and despite being on treatment with enzyme replacement therapy, our patient developed right bundle branch block and had an unexplained loss of consciousness. His recent symptomatology and the history of non-sustained VT prompted the implantation of an internal cardioverter defibrillator. He subsequently developed complete heart block and had an episode of VT successfully terminated by the device. The renal dysfunction did not progress.

\section{DISCUSSION}

AFD is an X linked disorder caused by mutations in the GLA gene which encodes for the lysosomal enzyme -galactosidase A. Reduction in -galactosidase A activity leads to accumulation of neutral glycosphingolipids, primarily globotriaosylceramide, in a variety of tissues leading to a multisystem disease with protean manifestations. After an asymptomatic phase, clinical manifestations develop in childhood and become exacerbated during adulthood. The survival of untreated males is 20 years less than males from the general population. Death occurs in middle age and beyond from cardiac, renal and neurological complications. In general, females have less severe disease but are not immune to life-threatening complications which generally occur later on in life. ${ }^{2} 3$

The classic cardiac manifestation is concentric LVH, but infrequently hypertrophy can be asymmetric, mimicking hypertrophic cardiomyopathy caused by sarcomeric gene mutations. Diastolic dysfunction dominates the early stages of the disease, and can progress to restriction and/or systolic impairment. As AFD is an X linked disease, hypertrophy is 


\section{BMJ Case Reports}

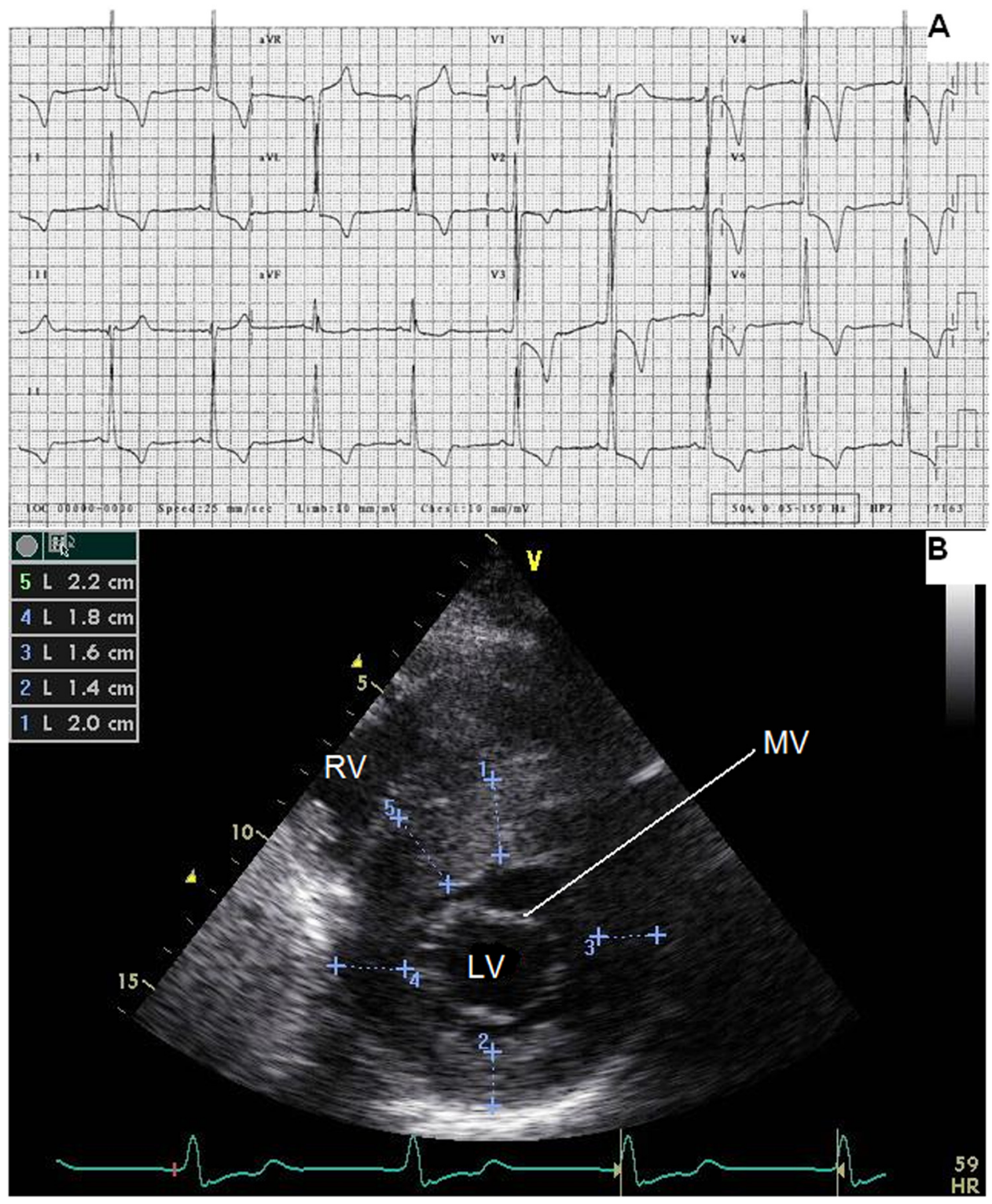

Figure 1 (A) ECG. (B) Parasternal short-axis view of the left ventricle. LV, left ventricle; MV, mitral valve; RV, right ventricle.

commoner and more severe in males, and also occurs at a younger age than females. ${ }^{2}{ }^{4}$ Electrocardiography typically shows LVH by voltage criteria, and one in five patients has a short PR interval. Atrial fibrillation and VT are encountered in $17 \%$ and $8 \%$ of patients, respectively. Conduction tissue infiltration causes sinus and atrio-ventricular node dysfunction, with a large minority requiring antibradycardia pacing. These arrhythmias may cause syncope, as well as sudden cardiac death. ${ }^{5}$

Proteinuria is an early manifestation of renal involvement, and aggressive treatment with angiotensin-converting enzyme inhibitors is recommended in an attempt to prevent progression to end-stage renal failure which afflicts males in their third decade of life. ${ }^{6}$

Ischaemic strokes and transient ischaemic attacks occur in up to one-quarter of patients, frequently in association with cardiac and renal disease. The vertebrobasilar and posterior circulations are most commonly affected. The aetiology of these events is probably related to small vessel disease caused by the deposition of globotriaosylceramide in vascular endothelium.

In addition to the life-threatening complications described above, AFD patients often have a myriad of other symptoms from multiple organ involvement. The earliest complaint is a 'burning' pain affecting the extremities (acroparesthesia) caused by small fibre neuropathy. Gastrointestinal symptoms are also common and include postprandial nausea, vomiting, abdominal pain, distention and irregular bowel habit. Vascular skin lesions (angiokeratomas) are often seen around the umbilicus, groin and trunk in a swimsuit distribution. Impaired sweating (hypohydrosis) and lymphoedema are caused by the accumulation of globotriaosylceramide in sweat glands and lymphatics, respectively. Patients frequently complain of sensorineural hearing loss, dizziness from vestibular dysfunction and tinnitus from inner ear involvement. ${ }^{38}$ A part from proteinuria, our patient did not have any other extracardiac manifestations. Predominant cardiac involvement is unusual and may 


\title{
BMJ Case Reports
}

relate to a number of specific GLA mutations, including N215S, where residual enzyme activity limits the development of AFD-related complications. ${ }^{9}$

Administration of recombinant-galactosidase $\mathrm{A}$ is the cornerstone of treatment. Randomised controlled trials are limited, but the data so far suggest that it may have a beneficial effect on conduction system disease and LVH, as well as stabilisation of renal function. ${ }^{23}$ There is some evidence to suggest that early treatment with enzyme replacement therapy, prior to the development of irreversible fibrosis secondary to globotriaosylceramide deposition is more effective. This may explain why our patient developed complications despite enzyme replacement therapy. ${ }^{10}$

Even though AFD is a rare disease with an estimated incidence of up to 1/40 000 live male births, this case illustrates the value of screening for AFD in patients with unexplained $\mathrm{LVH}$, especially if the hypertrophy is concentric because the prevalence in this group can be up to $4 \% .^{2}{ }^{3}$ AFD should also be considered in young patients with unexplained cerebrovascular accidents or renal disease. ${ }^{3}$ Associated symptoms such as acroparesthesia may provide clues to the diagnosis but are not invariably present as illustrated by our patient. Identifying patients with AFD is important because effective treatment has now become available and family screening for AFD enables the detection and treatment of preclinical disease, for example, proteinuria to prevent longterm complications in affected relatives.

\section{REFERENCES}

1. Elliott $\mathbf{P}$, Andersson B, Arbustini E, et al. Classification of the cardiomyopathies: a position statement from the European Society Of Cardiology Working Group on Myocardial and Pericardial Diseases. Eur Heart $J$ 2008;29:270-6.

2. O'Mahony C, Elliott P. Anderson-Fabry disease and the heart. Prog Cardiovasc Dis 2010;52:326-35.

3. Zarate YA, Hopkin RJ. Fabry's disease. Lancet 2008;372:1427-35.

4. Linhart A, Kampmann C, Zamorano JL, et al. Cardiac manifestations of Anderson-Fabry disease: results from the international Fabry outcome survey. Eur Heart J 2007;28:1228-35.

5. Shah JS, Hughes DA, Sachdev B, et al. Prevalence and clinical significance of cardiac arrhythmia in Anderson-Fabry disease. Am J Cardiol 2005;96:842-6.

6. Breunig $\mathbf{F}$, Wanner $\mathbf{C}$. Update on Fabry disease: kidney involvement, renal progression and enzyme replacement therapy. J Nephrol 2008;21:32-7.

7. Moore DF, Kaneski CR, Askari $\mathrm{H}$, et al. The cerebral vasculopathy of Fabry disease. J Neurol Sci 2007;257:258-63.

8. Mehta A, Ricci R, Widmer U, et al. Fabry disease defined: baseline clinical manifestations of 366 patients in the Fabry Outcome Survey. Eur J Clin Invest 2004; 34:236-42.

9. Nakao S, Takenaka T, Maeda M, et al. An atypical variant of Fabry's disease in men with left ventricular hypertrophy. N Engl J Med 1995;333:288-93.

10. Weidemann F, Niemann M, Breunig F, et al. Long-term effects of enzyme replacement therapy on fabry cardiomyopathy: evidence for a better outcome with early treatment. Circulation 2009;119:524-9.

\section{Learning points}

- AFD is responsible for unexplained LVH in up to $4 \%$ of cases.

- AFD is commonly associated with multiple symptoms from an early age.

- Males have more severe disease than females.

- Cardiac, renal and cerebrovascular complications are responsible for early mortality.

- Recombinant enzyme replacement therapy is the cornerstone of treatment.

Competing interests None.

Patient consent Obtained.

\author{
This pdf has been created automatically from the final edited text and images. \\ Copyright 2010 BMJ Publishing Group. All rights reserved. For permission to reuse any of this content visit \\ http://group.bmj.com/group/rights-licensing/permissions. \\ BMJ Case Report Fellows may re-use this article for personal use and teaching without any further permission. \\ Please cite this article as follows (you will need to access the article online to obtain the date of publication). \\ Cauti FM, O'Mahony C, Pantazis A. Cardiac involvement in Anderson-Fabry disease. BMJ Case Reports 2010;10.1136/bcr.02.2010.2760, date of publication \\ Become a Fellow of BMJ Case Reports today and you can: \\ - Submit as many cases as you like \\ - Enjoy fast sympathetic peer review and rapid publication of accepted articles \\ - Access all the published articles \\ - Re-use any of the published material for personal use and teaching without further permission \\ For information on Institutional Fellowships contact consortiasales@bmjgroup.com \\ Visit casereports.bmj.com for more articles like this and to become a Fellow
}

